\title{
TECNOLOGIA, EDUCAÇÃO E EDUCAÇÃO TECNOLÓGICA: HERANÇAS E ENDEREÇAMENTOS
}

\author{
Joice Yuko Obata * \\ Luciane Ferreira Mocrosky ${ }^{* *}$ \\ Marco Aurélio Kalinke***
}

\begin{abstract}
Resumo: Este artigo visa discutir significados atribuídos à tecnologia e à produção de conhecimento com a tecnologia no contexto escolar, tendo por pano de fundo sentidos destes na Educação Matemática. Em atenção à interrogação orientadora "Que compreensões podem ser possíveis quando visamos o encontro tecnologia-educação?" estudamos autores que se dedicam ao tema, buscando suporte de fundo teórico-filosófico para respondê-la. Deste estudo delineamos um percurso de exposição de nossas compreensões, iniciando com uma seção que visa demarcar a inserção da tecnologia na educação brasileira. Seguimos, abrindo uma discussão sobre matizes históricas das tecnologias na Educação Matemática no Brasil e finalizamos nosso texto dialogando com as ideias de Martin Heidegger, em direção a um entendimento de educação tecnológica. Para este autor o "ter" e "usar" tecnologias solicitam ser vistas no movimento do produzir conhecimento, transformando o aprender e o ensinar, de modo a habitar o mundo adjetivado de tecnológico.
\end{abstract}

Palavras-chave: Educação. Tecnologia. Educação Matemática. Produção de Conhecimento. Educação Tecnológica.

\section{Introdução}

O mundo em que vivemos, a sociedade da qual fazemos parte, tem revelado a presença da tecnologia como fundamental para a produção de conhecimento, nos mais diversos campos e organizações socioculturais. Bazzo (2011) alerta para a importância de a escola não ficar à margem desse complexo movimento produtivo. Porém, afirma que o enfrentamento dos desafios de uma educação para a contemporaneidade passa,

\footnotetext{
* Mestra em Educação em Ciências e em Matemática pela Universidade Federal do Paraná-PR. Professora do Centro Social Marista Ecológica de Almirante Tamandaré-PR.

** Doutora em Educação Matemática. Professora do Departamento Acadêmico de Matemática da Universidade Tecnológica Federal do Paraná (UTFPR, Curitiba); Professora do Programa de Pós-Graduação em Educação em Ciência e em Matemática (PPGECM-UFPR) e do Programa de Pós-Graduação em Formação Científica, Educacional e Tecnológica (PPGFCET-UTFPR).

*** Doutor em Educação Matemática. Professor do Departamento Acadêmico de Matemática da Universidade Tecnológica Federal do Paraná (UTFPR, Curitiba); Professor do Programa de Pós-Graduação em Educação em Ciência e em Matemática (PPGECM-UFPR) e do Programa de Pós-Graduação em Formação Científica, Educacional e Tecnológica (PPGFCET-UTFPR).
} 
necessariamente, pela formação do professor que supere aspectos práticos da profissão, bem como os técnicos da ciência a ser ensinada (BAZZO, 2011). Em tal ciência, disciplinarizada, em se tratando de tecnologia, muitas vezes as vozes no interior da escola ecoam fortemente para a denúncia da falta da materialidade tecnológica, como equipamentos, laboratórios, projetos para o uso de destes e, também, de verbas que possibilitem ampliar tais ambientes e programas que, segundo Mocrosky et al. (2016), iluminam a precisão do ter sobre o ser. Ter é preciso! Mas, qual ênfase se tem dado à precisão?

Relutamos em aceitar que, para uma efetiva mudança, o caminho não passa pelo
estabelecimento de recursos materiais cada vez mais sofisticados. Iludidos por esse
discurso de sempre, continuamos deixando em segundo plano a formação didático-
pedagógica e epistemológica dos professores e as reflexões sobre aonde as
decantadas revoluções tecnológicas estão nos levando como seres humanos
(BAZZO, 2011, p.12).

Nesse sentido, Ponte (2002) discute a formação de professores, em especial daqueles que ensinam matemática, apontando a importância da tecnologia como presença articuladora do projeto formativo das pessoas, de modo que estejam em jogo atitudes e valores que possibilitem uma educação transformadora.

Entende-se, assim, que não é suficiente ter equipamentos e manter o professor em contato com a aprendizagem das tecnologias adquiridas pela escola, mesmo que com estas contemple-se os conteúdos que o professor ensinará. Conforme os autores já citados, e no encontro com Kenski (2007, p. 44), “a presença de uma determinada tecnologia pode induzir profundas mudanças na maneira de organizar o ensino" nesse mundo, comumente adjetivado de tecnológico.

O "tecnológico", que vem qualificando a era em que vivemos, muitas vezes deixa em destaque o entendimento de que a sociedade conta cada vez mais com o aparato tecnológico para favorecer a disseminação da informação e a comunicação entre as pessoas. Pautados nesse entendimento, nos perguntamos: se assim for, a tarefa docente seria cuidar disso que desenfreadamente chega até nós? Mas, quem dispõe tais informações? Como elas são produzidas? Que comunicação vem sendo possível nesse mundo tecnológico? Mais ainda, como a escola vive esse movimento, ou, como a escola vem pulsando nesta sociedade tecnológica? A escola é viva, dinâmica e, por assim ser, também tem a possibilidade de se modificar, haja vista que ela está aí, sendo escola, carregando consigo as complexidades que permeiam a vida das pessoas. 


\section{\#tear}

As respostas para estas perguntas não estão prontas e nem são elaboradas imediatamente. A tentativa de respondê-las exige construir um caminho que favoreça a compreensão acerca do que vem qualificando a sociedade de tecnológica, para avançarmos na elaboração e no habitar, na concepção de Heidegger (2012), do projeto que vise o ser humano, pois como Bazzo (2016) nos alerta

[...] parece que de tempos para cá as pesquisas sobre o desenvolvimento tecnológico colocaram para escanteio aquelas produzidas sobre o desenvolvimento humano de forma articulada e inseparável. Isso é grave! Muito grave (BAZZO, 2016, p.75).

Com o intuito de clarear significados atribuídos à tecnologia e à produção de conhecimento com a tecnologia no solo escolar, o presente texto tratará dos matizes de um olhar histórico pela educação brasileira, orientada pela pergunta: "que compreensões podem ser possíveis quando visamos o encontro tecnologia-educação?”.

Nesse sentido, a importância das discussões sobre tecnologia e educação suplantam ter equipamentos e cursos específicos para saber usar o que se tem. Nesse horizonte que se abre, é importante deixar cada vez mais em evidencia estudos com vistas à Educação Tecnológica. Apesar de sabermos que a expressão "Educação Tecnológica" comparece mais no contexto da Educação Profissional, a academia tem demonstrado um apelo em considerá-la mais amplamente, de modo a abranger educação nos mais diversos campos do conhecimento.

Neste artigo nos ocupamos em expor a compreensão que vimos tendo do assunto, pelo estudo ${ }^{1}$ de textos de autores que de algum modo abordam educação, tecnologia, nos colocando no caminho de abrir clareiras para o entendimento da produção do conhecimento, ao pôr em destaque aspectos filosóficos e históricos que favoreceram delinear contornos de uma Educação Tecnológica no âmbito da Educação Matemática. Para desenvolver este trabalho, fruto de uma investigação qualitativa, recorreu-se a um estudo teórico e reflexivo, cujo modo de proceder encontrou sustentação metodológica nos trabalhos de Bicudo (2005; 2011).

Para delinear um percurso de exposição de nossas compreensões, iniciamos o artigo com uma seção que visa demarcar a inserção da tecnologia na educação brasileira. Seguimos, abrindo uma discussão sobre matizes históricas das tecnologias da informação e comunicação

\footnotetext{
${ }^{1}$ Estudos realizados no Grupo de Estudos e Pesquisa em Formação de Professores (GEForProf) e no Grupo de Pesquisas sobre Tecnologias na Educação Matemática (GPTEM), ambos sediando na Universidade Tecnológica Federal do Paraná (UTFPR), cujos segundo e terceiro autores, respectivamente, orientaram e co-orientaram o mestrado da primeira autora.
} 
(TIC) na Educação Matemática no Brasil e finalizamos nosso texto dialogando com as ideias de Heidegger, em direção a um entendimento de educação tecnológica.

\section{Tecnologias na educação brasileira: um acontecer histórico}

Buscar por um marco para a inserção de tecnologias no ensino no Brasil, não é uma tarefa fácil, pois nem sempre o que vem sendo registrado na história da educação dá conta de explicitar as experiências vividas de professores. Com isso, as marcas ficam do que vem orientando políticas públicas para a educação. Sobre isso, Bicudo (1999, p. 8) diz que a presença das tecnologias no ensino e "na Educação Matemática se dá pela própria atividade desenvolvida na educação, de transmissão das técnicas culturais construídas ao longo da História pelas gerações de homens e mulheres". Portanto, para a tentativa de trazer as primeiras iniciativas de inserção das TIC no ensino da Matemática brasileira, foi necessário recorrer de forma mais abrangente à educação para então, adentrar o campo da Educação Matemática.

Os primeiros anos da década de 1980 constam como marco inicial da inserção das TIC no Brasil, principalmente as tecnologias informáticas por meio de políticas públicas governamentais, influenciadas por países como Estados Unidos e França (VALENTE, 1999). Entretanto, as ideias e discussões para tal já vinham ocorrendo desde a década de 1970.

Moraes (1997) traz um breve histórico de como se deu o início do uso da tecnologia informática na educação brasileira e indica que, em julho de 1975, a Universidade Estadual de Campinas (UNICAMP) recebeu a visita de Seymour Papert e Marvin Minsky que lançaram as primeiras ideias da linguagem de programação "LOGO". Os pesquisadores retornaram à UNICAMP no ano seguinte para ministrar seminários e participar de atividades de pesquisas que tinham se estabelecido sobre o uso do LOGO em educação. Em fevereiro e março de 1976, um grupo de pesquisadores da Universidade de Campinas visitou o Instituto de Tecnologia de Massachusetts (MIT) e originou investigações brasileiras sobre o computador na educação, especialmente sobre o LOGO.

Segundo Moraes (1997), as primeiras ações do governo federal para informatizar a sociedade brasileira, estabelecendo políticas públicas objetivando uma maior segurança e desenvolvimento da nação, ocorreram em meados da década de 1970. Com esta intenção, criou-se em 1979 a Secretaria Especial da Informática (SEI), que tinha por finalidade 


\section{\#tear}

regulamentar, supervisionar e fomentar o desenvolvimento científico e tecnológico em diferentes setores da indústria brasileira.

Para discutir estratégias de planejamento que refletissem as preocupações e o interesse da sociedade brasileira, foi promovido o I Seminário Nacional de Informática na Educação na Universidade de Brasília em 1981, que contou com a presença de educadores de diversos estados brasileiros e especialistas nacionais e internacionais. Esse seminário é considerado o marco inicial das discussões sobre informática na educação, destacando a importância de se pesquisar o uso do computador como ferramenta auxiliar nos processos de ensino e aprendizagem, principalmente em relação às políticas públicas que foram estabelecidas (MORAES, 1997; BORBA; PENTEADO, 2012; ALMEIDA, 2008a; 2008b).

Em virtude das discussões ocorridas nesse evento, surgiu a ideia da implantação de projetos-piloto em universidades cujas investigações ocorriam em caráter experimental e deveriam servir de subsídios a uma futura política nacional de informatização da educação. As universidades que apresentaram perfil para tal projeto foram: a Universidade Federal do Rio de Janeiro, a Universidade Federal do Rio Grande do Sul, Universidade Federal de Minas Gerais e a Universidade Federal de Pernambuco. As ações foram viabilizadas pelo Projeto Educação com Computador (EDUCOM), que foi apresentado em março de 1983 após discussões originadas no II Seminário Nacional de Informática na Educação realizado em janeiro de 1983.

Em 1987, após a Jornada de Trabalho de Informática na Educação, ocorrida em Florianópolis, a qual contou com a participação de profissionais envolvidos com a pesquisa e produção na área, bem como com profissionais de escolas e empresas que atuavam no setor, o Ministério da Educação (MEC) criou o Projeto FORMAR que tinha por objetivo capacitar professores para atuar como multiplicadores. Essa capacitação era operacionalizada por meio de dois cursos de especialização em informática na educação, em nível de pós-graduação lato sensu, realizados na UNICAMP, em 1987 (FORMAR I) e 1989 (FORMAR II) (MORAES, 1997; BORBA; PENTEADO, 2012). De iniciativa do projeto FORMAR, foram implantados 17 Centros de Informática Educativa (Cied) pelo Brasil.

Os Cieds constituíram-se em centros irradiadores e multiplicadores da tecnologia da informática para as escolas públicas brasileiras, os principais responsáveis pela preparação de uma significativa parcela da sociedade brasileira rumo a uma sociedade informatizada (MORAES, 1997, p. 29). 
Em outubro de 1989, pela da Portaria Ministerial n 549, foi instituído o Programa Nacional de Informática Educativa (Proninfe) que tinha os objetivos de apoiar o desenvolvimento e a utilização de informática educativa nas áreas de ensino de $1^{\circ}, 2^{\circ}$ e $3^{\circ}$ graus (atuais ensinos fundamental, médio e superior) e de educação especial, promover e incentivar a capacitação de recursos humanos no domínio da tecnologia de informática educativa, estimular e disseminar resultados de estudos e pesquisas de aplicação da informática. Também objetivava acompanhar projetos voltados para o uso de computador nos processos educacionais.

Segundo Valente (1999) e Moraes (1997), em 1997, o MEC lançou o Programa Nacional de Informática na Educação (ProInfo), vinculado à Secretaria de Educação a Distância, criada em 1996. Esse programa objetivava "estimular e dar suporte para a introdução de tecnologia informática nas escolas do nível fundamental e médio de todo o país" (BORBA; PENTEADO, 2012, p. 20). O ProInfo funcionava de forma descentralizada, cuja coordenação era de responsabilidade federal e a operacionalização conduzida pelos estados e munícipios. Desde o surgimento, esse programa implantou mais de 244 Núcleos de Tecnologia Educacional (NTE) e investiu na formação de mais de 20 mil professores por meio das NTE em diversas partes do país. Atualmente o ProInfo ainda se encontra em plena atividade e, em uma análise mais detalhada, Richit e Maltempi (2013) citam dois programas promovidos pelo MEC, que se articularam com o ProInfo: o Programa Um Computador por Aluno (PROUCA), criado em 2007, e o programa ProInfo Integrado, criado em 2008.

Esses dois programas buscavam promover a inclusão digital das escolas públicas da educação básica por meio da distribuição de um computador portátil para cada estudante e professor dessas instituições. O PROUCA, com financiamento federal, possibilitou a aquisição de computadores portáteis pelas escolas públicas brasileiras objetivando a inclusão escolar. Em relação a este programa, no que tange à questão da formação de professores que ensinam Matemática nos anos iniciais:

As ações efetuadas nem sempre trazem avanços e condições para que a inclusão digital aconteça. Se por um lado a proposta anuncia educação e inclusão digital como parte de um mesmo movimento, por outro há a prevalência da perspectiva conteudista da escola e de um retroceder no entendimento de formação de professores apenas pelo viés de treinamento (ORLOVSKI; KALINKE; MOCROSKY, 2014, p. 83).

Ao buscar na literatura indícios da inserção de TIC na educação brasileira, na maioria das vezes a encontramos relacionada à formação dos professores na área de 
informática na educação, no entanto, o preparo de docentes era voltado para uma mudança pedagógica que não focasse apenas o formar professores para aprender a usar o computador, conforme constatou Valente (1999). E no que tange ao uso da tecnologia nos processos de ensino da Matemática, o que a literatura nos diz?

\section{As tecnologias na Educação Matemática}

Lançando olhares à trajetória das tecnologias na Educação Matemática desde os anos de 1980, encontramos em Borba, Silva e Gadanidis (2016) quatro fases das tecnologias digitais. Estes autores destacam que mesmo apontando supostas fronteiras que distinguem uma fase da outra, o surgimento de cada uma não excluía ou substituía a anterior, pois ocorria uma "sobreposição" entre elas e uma articulação que possibilitou que se integrassem.

A primeira fase foi marcada pelo software LOGO, por volta dos anos de 1980, mesmo que já nesse período se falasse do uso de calculadoras e computadores em Educação Matemática. Destacam-se nesse cenário os trabalhos de

José Armando Valente, Janete Frant, Lulu Healy e Léa Fagundes. Eles desempenharam papéis fundamentais com relação à produção de conhecimentos na área de Educação Matemática baseados em investigações acerca de possibilidades do uso de TI na transformação de práticas pedagógicas e didáticas (BORBA; SILVA; GADANIDIS, 2016, p. 18).

Os trabalhos desse período são fundamentados na concepção teórica do construcionismo de Papert e na perspectiva de que as escolas deveriam ter laboratórios de informática, cuja implementação se iniciou no projeto EDUCOM, explicitado anteriormente.

A segunda fase teve início em meados dos anos de 1990. Ela foi marcada pelos softwares educacionais e foi impulsionada por conta das iniciativas de políticas públicas e programas governamentais, já discutidos anteriormente, como o ProInfo. Por meio dessas iniciativas, o professor encontrava alternativas de formação continuada e suportes para usar as TIC na sala de aula. Destacam-se, nessa fase, softwares que exigiam pouca ou nenhuma familiaridade com linguagem de programação e ainda tinham uma natureza dinâmica, visual e experimental (BORBA; SILVA; GADANIDIS, 2016). Entre os softwares que se destacaram na Educação Matemática estão aqueles voltados às múltiplas representações de funções (Winplot, Fun e Graphmathica), os de geometria dinâmica (GeoGebra, Cabri Géomètre e o Geometricks) e os gráficos (Derive, Winplot e Graphmathica). Desenvolveu-se uma vertente 
pensamos-com-tecnologias, ou seja, de trabalhar com a matemática e a tecnologia de forma coletiva e que possibilite a investigação Matemática.

A terceira fase se inicia em meados de 1999 com o advento da internet, que era usada na educação como meio de comunicação ou fonte de informações nos cursos a distância para a formação continuada de professores (BORBA; SILVA; GADANIDIS, 2016). Nessa fase os ambientes virtuais de aprendizagem ganham forças e, para os autores, ela se encontra em pleno desenvolvimento e ao mesmo tempo que transformou os softwares da segunda fase, vai sendo influenciada por novas possibilidades da fase seguinte.

Na esteira dos cursos a distância para formação de professores, Mocrosky, Mondini e Baumann (2014) estudaram a Educação a Distância (EaD) numa perspectiva histórica, procurando evidenciar a trajetória ancorada nos documentos da legislação brasileira. Estas pesquisadoras constaram que não há menções explícitas na lei em relação ao ensino da Matemática ou à Licenciatura em Matemática. A EaD na legislação aponta apenas o aspecto de como se dá a organização da modalidade para a instituições de ensino, se mostrando como possibilidade de formação docente em larga escala.

Por fim, a quarta fase, que teve início em meados de 2004 com o advento da internet rápida, trata-se do período que estamos vivenciando com relação ao uso das tecnologias em Educação Matemática. É nessa fase que o termo "tecnologia digital" se tornou comum, caracterizada por diversos aspectos como a multimodalidade, novos designs e interatividade, tecnologias móveis ou portáteis, e performance Matemática digital. Portanto, essa fase se mostra um cenário fértil para o desenvolvimento de investigações e à realização de pesquisas.

A este respeito e tendo por pano de fundo as primeiras iniciativas de inserção sobre as TIC na educação, constatou-se que cada período foi marcado por uma perspectiva pedagógica diferente, como é o caso dos anos denominados como "período LOGO”.

O LOGO é uma idealização prática do que preconiza o construcionismo, tal como defendido por Papert, influenciado pelas ideias construtivistas de Piaget. A teoria construtivista defende que o conhecimento se dá ativamente pelo sujeito cognoscente, não sendo passivamente recebido do ambiente. O aluno tem um papel ativo na construção do conhecimento enquanto o professor é um mediador do conhecimento. Embora Piaget não tenha se preocupado em criar uma teoria de ensino ou de aprendizagem, suas ideias trouxeram diversas contribuições para o ensino da Matemática (FIORENTINI, 1995). 
Maltempi (2004) entende que o construcionismo é tanto uma teoria de aprendizagem quanto uma estratégia para construção, que compartilha a ideia construtivista de que o desenvolvimento cognitivo é um processo de construção e reconstrução das estruturas mentais, sendo que o conhecimento não pode ser simplesmente transmitido do professor para o aluno.

Nesta quarta fase, além do construcionismo, evidenciam-se as perspectivas pedagógicas da experimentação e visualização possibilitadas pelos softwares de Geometria Dinâmica e gráficos, conforme indicado em Borba, Silva e Gadanidis (2016), Isotani e Brandão (2013).

Borba, Silva e Gadanidis (2016) entendem que a experimentação e visualização são elementos que aparecem na segunda fase e influenciam fortemente o ensino de Matemática com tecnologias. Eles entendem a experimentação com tecnologias como o "uso de tecnologias informáticas no estudo de conceitos ou na exploração de problemas matemáticos" (BORBA; SILVA; GADANIDIS, 2016, p. 51).

Com o uso de tecnologias, os objetos matemáticos passaram a ser representados digitalmente. Como isso apresentava aspectos de ineditismo, as simulações e a virtualidade expandiram os limites do caráter visual, entre outras modificações causadas pelo uso da tecnologia. A visualização altera a forma como se dá o pensamento matemático envolvendo um esquema mental que representa a informação visual ou espacial. "Ela oferece meios para que conexões entre representações possam acontecer" (BORBA; SILVA; GADANIDIS, 2016, p. 53).

A experimentação e visualização também aparecem em Isotani e Brandão (2013) como fatores importantes no ensino da Matemática com tecnologias, quando os autores falam sobre os benefícios e aplicações de especificamente uma tecnologia, o sistema computacional de Geometria Interativa, entendida por Isotani e Brandão (2013, p. 169), como "a implementação computacional da geometria tradicional, aquela de régua e compasso".

Embora a Geometria Interativa não possa provar teoremas, a capacidade de experimentação de hipóteses pode motivar a busca pela prova de um teorema, pois induz à convicção de sua validade. Da mesma forma, pode ajudar e sugerir caminhos para a prova formal (ISOTANI; BRANDÃO, 2013, p. 173, grifo nosso).

Por outro lado, pelo viés filosófico, em relação à interação homem-máquina, Figueiredo (2014) questiona o sentido em computação, entendendo que o mostrado na tela do 


\title{
\#tear
}

computador não passa de interfaces que definem novas experiências na relação do homem com a máquina, podendo ser entendidas como esconderijos dos códigos.

\begin{abstract}
No caso da computação, o grande obstáculo a ser superado para que um sentido puramente maquinal se estabeleça são as interfaces. E de todos os aspectos presentes nas interfaces, aquele que causa mais distanciamento entre o homem e a máquina é o visual, pois a visualização já traz consigo compreensão do percebido (MERLEAUPONTY, 2006 apud FIGUEIREDO, 2014, p. 142-143).
\end{abstract}

Para esse autor, mesmo que haja a compreensão de que o que se vê na tela de um computador não passe de projeção de códigos, em que um triângulo, por exemplo é um conjunto de pontos projetados por coordenadas cartesianas, ainda assim nos causam fascínio, pois "na visualização de imagens, enlaçamos os sentidos" (FIGUEIREDO, 2014, p. 143). Portanto, concordando com as palavras desse autor, "a computação com máquinas está aí. Ela se imiscuiu em todos os aspectos de nossas vidas" (FIGUEIREDO, 2014, p. 148).

Daí a importância da filosofia quando se fala de TIC, pois o fascínio causado pela tecnologia provoca uma visão romantizada da inteligência artificial e entender que a computação é um formalismo ajuda a quebrar certas expectativas, como nos diz Figueiredo (2014), nos conduzindo ao estado de endeusamento dessas ferramentas (BAZZO, 2011).

\section{Tecnologia e educação: nos rumos de uma educação tecnológica}

Atualmente tem sido frequente conceber a tecnologia no contexto da educação como um recurso pedagógico ou uma ferramenta de trabalho sem a qual não se produz conhecimento para enfrentar as complexidades do mundo em que vivemos. Ainda, ao se falar em tecnologia no âmbito da educação, o que vem se sobressaindo é a expressão "tecnologia educacional" (CANDAU, 1979) ou "informática na educação" (VALENTE, 1999), sendo o computador um ícone da era tecnológica. Computador e softwares ganham visibilidade muito mais como instrumentos do que no modo de produzir conhecimento.

No caminho das discussões sobre o tema, encontramos em Candau (1979), Mello (1989), Grinspun (1999), Valente (1999), Kenski (2007), Richit (2010), Bazzo (2011), Mocrosky e Bicudo (2013), e Kalinke e Mocrosky (2016) diferentes compreensões que conduziram a denominações ou rótulos a respeito da tecnologia, assim anunciadas: tecnologias digitais em educação, tecnologia educacional, educação para tecnologia, educação com tecnologia, educação tecnológica, tecnologia da informação e comunicação na educação, 
tecnologia e educação, tecnologia na educação, tecnologia da educação, e informática na educação.

Pelas leituras efetuadas, vimos que há uma falta de clareza e esta tem escondido significados de tecnologia e produção de conhecimento na escola pela inflação de termos, como já vinha sendo apontado por Mello (1989) no final da década de 1980. Essa autora afirma que muitas vezes os termos que tentavam expressar o momento das novas tecnologias na escola eram usados como sinônimos.

Para Oliveira et al. (2007), essa confusão e multiplicidade de termos ainda permanece. Em um estudo realizado com professores constaram que a expressão "educação tecnológica" foi concebida pelas participantes da pesquisa, que a usavam como sinônimo de educar o aluno para o uso da tecnologia. Tal investigação revela que as professoras entrevistadas entendem que tecnologia está relacionada aos recursos usados na educação. Richit (2010), que também ouviu docentes em momento destinado à formação tecnológica, constatou que muitos professores do século XXI ainda se referem à tecnologia como algo complementar, como uma atividade que possa contribuir com o reforço de algo ensinado. Pode-se dizer um adereço, algo que tem o potencial de enfeitar, mas que nem sempre dá conta do proposto.

Assim, Oliveira et al. (2007) afirmam que para uma parte dos sujeitos, educação, tecnologia e tecnologia educacional vem acompanhada de incompreensões. Os professores colaboradores da investigação, ao explicitarem que a educação tecnológica é aquela que habilita o aluno a usar a tecnologia, abrem possibilidade de as pesquisadoras entenderem, no percurso investigativo, que a educação tecnológica “[...] apresenta enfoque na utilização de produtos e poucas vezes há um questionamento acerca da maneira como se dá o desenvolvimento tecnológico na sociedade" (OLIVEIRA et al., 2007, p. 8-9). Bazzo (2011), na mesma direção de Mello (1989), por meio de exposições situadas em dois séculos distintos e em um intervalo de aproximadamente 20 anos, enfatiza a alienação como uma das faces da tecnologia na sociedade. Tal alienação vem revestida da falta de crítica a respeito do que produzimos e do como produzimos na contemporaneidade, dificultando o pensar nos aspectos histórico-sociais que a tecnologia tem provocado na sociedade.

Produzir conhecimento é a fala comum entre os autores, mas que significados se escondem quando tratamos do produzir escolar? Na academia, o conhecimento produzido é conferido à ciência, que atualmente se mostra de modo disciplinar, embora esteja envolta no 
discurso das amálgamas entre disciplinas para, nos dias atuais, produzir o novo ou reelaborar o existente. Estas separações entre áreas científicas, que vem como herança da era moderna, cada vez mais tem contado com processos técnicos requintados, maquinísticos e maquinários, conhecidos pela alcunha de tecnologia.

Vimos, também, nos autores já citados, que tecnologia e produção são termos que vêm permeando o discurso escolar e industrial, muitas vezes aproximando o produzir na escola a um modelo fabril, fortemente visto nas décadas de 1960, quando o país tentava enfrentar as dificuldades de industrialização e a escola participaria na formação de profissionais para atender essa necessidade, qual seja, mão de obra qualificada. Mocrosky et al. (2016) e Mocrosky (2010) ao discutirem estas questões, encontram na formação profissional a nascente do termo Educação Tecnológica, em que tecnológico vem associado a um parque industrial que exigia e ainda exige instrumentos e máquinas. Daí afirmar que estes se tornaram ícones da tecnologia.

Bazzo (2011), explicita que, historicamente, as pessoas se referiram à tecnologia e à técnica como utensílios, ferramentas, instrumentos e máquinas. Compreende que ela está ligada às transformações consecutivas dos diferentes artefatos usados pelo homem com sentido estrito de ferramenta, sendo entendida ao longo da história como arte, produção e manutenção de instrumentos. Este autor alerta que tal "entendimento, sempre procurou não levar em consideração as inter-relações dentro do entorno que abrange o sistema e o ser humano", pois de certa forma, a técnica se transformou ao longo do tempo através dos diferentes artefatos, porque ela influenciou na organização social. Isso posto, tal aspecto deve ser considerado ao se falar da técnica, o que não acontece na maioria da bibliografia sobre o tema (BAZZO, 2011, p.115).

\section{Educação, Tecnologia e Educação Tecnológica: em busca de elos}

No Brasil a educação tecnológica se encontra intimamente relacionada com a educação profissional que surgiu, de acordo com Nascimento (2007, p. 282), “em função da demanda de mão-de-obra oriunda das novas condições tecnológicas que se implantavam no país e, principalmente pelas pressões sociais exercidas pelos jovens que queriam o aumento de vagas no ensino superior [...]”. Portanto, esses dois fatores, em especial, revolucionaram o ensino profissional fazendo com que a educação profissional acenasse para a educação tecnológica. 
A literatura mostra que a educação tecnológica no Brasil é gestada pela educação profissional no período marcado pelo surto de industrialização, no início da República, sendo criadas as Escolas de Ofício e Artífices, em 1909, por Nilo Peçanha. Isso porque, por volta dos anos de 1900, o advento da indústria e do comércio "demandavam não apenas uma instrução Matemática mais ampla, como também conhecimentos mais modernos e avançados que servissem de base para aplicações técnicas" (VALENTE, 2004, p. 12). À época, não apenas a educação profissional passava por mudanças, mas também a Matemática era modificada por ela. Basta atentar à Reforma Capanema, que em 1942 organizou o ensino técnico-profissionalizante, época em que foi instituída a rede de instituições de ensino industrial. Na esteira de tal reforma, em 1959 cria-se a Rede Federal de Ensino Técnico e as Escolas Técnicas Federais que passaram a ofertar um ensino de maior qualidade (NASCIMENTO, 2007). Essa valoração para a qualidade se mostrou pela exigência de mais ciência na formação de profissionais e, com isso, em 1974 surgiram os primeiros cursos de curta duração de Engenharia de Operação em diversas instituições do país. No que se refere à Matemática nesses cursos:

\begin{abstract}
A sua importância mostrava-se mais evidente nas seguintes situações: a alta taxa de evasão escolar, pois a permanência dos alunos nos cursos dependia de "boa base Matemática"; e o raciocínio, considerando que a Matemática era vista como a responsável pelo desenvolvimento do raciocínio, principalmente para a aprendizagem, domínio e aplicação de técnicas específicas [...] (MOCROSKY, 2010, p. 12).
\end{abstract}

Retomando a busca pelos possíveis significados de Educação Tecnológica, Grinspun (1999) entende que a expressão não possuiu um consenso, uma vez que ela é compreendida de acordo com o ponto de vista de vários mundos, como da educação, do trabalho, da produção, dos conhecimentos, da necessidade de novas metodologias ou da filosofia da tecnologia.

Mas falar de tecnologia com o olhar atento nos encaminha a pensar em modos de produzir com a tecnologia que temos aí à disposição ou aqueles que poderemos desenvolver por conta de projetos específicos em que a tecnologia vigente e a ciência nos permitam avançar. Falar disso significa falar de algo que sempre esteve presente na vida das pessoas, a técnica. Mas, que significados podem ser atribuídos à técnica? Ou melhor, o que ela pode significar? As perguntas não param por aí: que compreensões de tecnologia vêm sendo apontadas nos autores estudados? 
Grinspun (1999) define tecnologia analisando etimologicamente a palavra, afirmando que provém da técnica, do vocábulo latino techné que significa arte ou habilidade; ou o saber fazer, como disse Vargas (1999). Assim, Grinspun caracteriza a tecnologia, de maneira geral, como:

Um conjunto de conhecimentos, informações e habilidades que provem de uma inovação ou invenção científica, que se operacionaliza através de diferentes métodos e técnicas que é utilizado na produção e consumo de bens e serviços (GRINSPUN,1999, p. 51).

Segundo a autora, a tecnologia não pode ser olhada isolada de um contexto histórico em que estejam em jogo relações sociais, afirmando ser a tecnologia um conhecimento científico transformado pela técnica "[...] que, por sua vez irá ampliar a possibilidade de produção de novos conhecimentos científicos” (GRINSPUN, 1999, p. 49).

Para Grinspun (1999), as tecnologias são interdependentes e se mostram por meio de duas formas, a primeira é a implícita, aquela que permite produzir um bem físico e se acha embutida em seu valor, em que os gastos são cobertos por patentes e assistências técnicas. A segunda é a explícita, aquela que, diferente da primeira, pode ser um objeto de comércio direto. Por esse caminho, a autora discute a importância da ciência para a tecnologia, já que "a ciência interage, intimamente, com a tecnologia, e esta com a sociedade" (GRINSPUN, 1999, p. 50). Esses três estão conectados à forma como a sociedade se organiza, pois a inserção da tecnologia modifica as ocupações e redimensiona o trabalho.

Entre autores que investem em estudos para a compreensão da tecnologia, encontramo-nos com Mello (1989). Esta pesquisadora afirma que seu objetivo não era entrar em um consenso para definir a tecnologia na educação, mas questionar e compreender tal expressão em sua multiplicidade. Ela procurou estudar significados de tecnologia, que muito se aproximam da forma como Grinspun (1999) buscou definir. Mello (1989) também se vale da palavra latina techné e, mais do que isso, se aprofunda e busca a "recuperação do sentido originário da techné dos gregos” (MELLO, 1989, p. 64). Ela diz que techné significa para os gregos um tipo de conhecimento, uma maneira de aparecer, um desvelar da verdade do ser, mesmo que seja concebida como arte aplicada ou manufaturada de artesanato manual. A techné envolve natureza e revelação, assim como entende Heidegger (2012). Na esteira dessa concepção grega de técnica, encontramos uma relação entre técnica e produção, ou seja, com a tecnologia é possível produzir conhecimento tendo a técnica como fio condutor e não apenas um instrumento. 


\section{\#tear}

Podemos aqui perguntar: o que está no âmago da técnica? Ou ainda: qual a sua essência? Para Lévy (1993), quando se busca pela essência da técnica, buscamos pelo que ela é, considerando que pode ser compreendida em seu acontecer histórico, ao ser buscada e repensada de tempos em tempos. Com esse pensamento nos encontramos com Heidegger (2012), para quem a técnica tem a ver com o futuro da humanidade, uma vez que sempre é possível novas visadas, portanto, desvelamentos.

Buscando uma compreensão sobre tecnologia, percebemos que a técnica está presente na maioria dos casos. Lévy (1993, p.10) nos diz que "a questão da técnica ocupa uma posição central". Levando em conta essa afirmação, verificamos que alguns autores, tais como Grinspun (1999) e Bazzo (2011), conceituam a tecnologia como um produto resultante da técnica e dos conhecimentos científicos. Bazzo (2011) não assume esta posição de modo direto, pois leva em consideração alguns fatores quando se tenta definir a tecnologia, tais como:

- $\quad$ tecnologia tem relação com a ciência, com a técnica e com a sociedade; - tecnologia integra elementos materiais - ferramentas, máquinas, equipamentos - e não materiais - saber fazer, conhecimentos, informações, organizações, comunicações e relações interpessoais;

- tecnologia tem relações com fatores econômicos, políticos e culturais;

- evolução da tecnologia é inseparável das estruturas sociais e econômicas de uma determinada sociedade (BAZZO, 2011, p. 117, grifo nosso).

Nessa toada, numa perspectiva heideggeriana, trazemos a interpretação de Mocrosky (2010) a respeito do entendimento da técnica como o sentido orientador da ciência moderna.

\footnotetext{
A modernidade, para Heidegger, é a era em que a técnica prepondera como modo de revelação da realidade, pautada na exploração da natureza traduzida como estrutura física, portanto, previsível e calculável.

A questão da técnica, em Heidegger, não ocorre num pensamento isolado, pois ele a toma como tema de reflexão ao relacioná-la com o destino do ser e, assim, busca compreender a relação homem-mundo não pela sociologia e nem pela psicologia, mas em termos ontológicos.

Em sua análise, Heidegger busca o sentido da técnica, transcendendo o fazer descolado da historicidade do ser e não o modo técnico ou tecnológico que tem guiado o ser-no-mundo. Ele se preocupou não com a técnica em si, mas com a questão da técnica que diz do futuro do homem e que, para ele, está intimamente ligado ao conhecimento operatório, fruto do pensamento calculador (MOCROSKY, 2010, p. 34).
}

Para Heidegger (2012, p. 11) técnica carrega consigo pelo menos duas determinações: "uma diz: técnica é meio para um fim. A outra diz: técnica é uma atividade do homem. Ambas as determinações da técnica pertencem reciprocamente uma à outra". Mas 
isso não é suficiente para defini-la! Esse filósofo busca a sua essência e isso significa dizer que ele pergunta pelo o que ela é, afirmando logo de início que a "técnica não é igual a essência da técnica" (HEIDEGGER, 2012, p. 11). Ele nos explica melhor dando o exemplo da essência da árvore: "que aquilo que rege toda a árvore, como árvore, não é, em si mesmo, uma árvore que se pudesse encontrar entre as árvores” (HEIDEGGER, 2012, p. 11).

Seguindo com seu pensamento, afirma: "Muito se diz que a técnica moderna ${ }^{2}$ é uma técnica incomparavelmente diversa de toda técnica anterior, por apoiar-se e assentar-se na moderna ciência exata da natureza" (HEIDEGGER, 2012, p. 18).

Buscamos no pensamento heideggeriano também uma tentativa de compreender a tecnologia, pois para Rodrigues (1999), Mocrosky (2010) e Mocrosky e Bicudo (2013), as ideias sustentadas por este filósofo têm importantes repercussões no mundo adjetivado de tecnológico desde o século XX.

Em Heidegger são fortes a crítica e a preocupação com o progresso científico em que isso arriscou tornar-se um progressivo distanciamento da questão do ser (FERNANDES, 2011; MOCROSKY, 2010). Heidegger sempre defendeu que a técnica é o a priori da ciência moderna e Mocrosky (2010) corrobora em sua tese argumentando que,

Como a técnica é um conhecimento ou um modo de conhecer, ela se destina ao
futuro e, portanto, interessa conhecer sua origem. Assim, entender a sua essência é
entender a sua origem, que coincide com a história da humanidade.
Embora a técnica tenha estado presente em todas as épocas e culturas, o caráter
técnico do mundo teve seu destaque na modernidade, pela racionalidade típica dessa
era em ter se mostrado apropriada a orientar o modo de ser do homem no mundo,
atrelando aos processos práticos e à busca das certezas a forma efetiva da
concretização da realidade: a realização do real pautada no modelo da ciência
(MOCROSKY, 2010, p. 33-34).

A técnica, que é tão antiga quanto a história da civilização humana, se entrelaça com a ciência a partir da era moderna até a contemporaneidade, surgindo daí a tecnologia numa concepção atualizada. Em uma tentativa de sintetizar as ideias heideggerianas sobre tecnologia, Mocrosky, Bicudo (2013) afirmam:

A tecnologia revela-se como uma área de complexidade que tem se constituído
através da ciência aplicada, mas uma aplicação dinâmica que solicita a ciência e sua
racionalidade e que não cabe apenas nessa racionalidade da ciência, pois abrange um
fazer técnico, mas não o reproduz: vai avançando por caminhos pelos quais se abrem
solicitações de estudos da lógica da tecno (tecno-logia), do aparato científico que a

2 Em Mocrosky e Bicudo (2013), numa perspectiva heideggeriana, encontramos o caminhar de duas racionalidades da técnica, a primeira delas concebida pelos gregos e a segunda pela ciência moderna (ocidental), de onde vem a expressão "técnica moderna", para diferenciar da técnica no entendimento dos gregos (techné). 
nutre e que é nutrido por ela. Portanto, a compreensão da técnica, da tecnologia e da ciência para além do que elas produzem em termos materiais, mostra o modo como a técnica, referida por Heidegger, está no âmago da ciência e da tecnologia (MOCROSKY; BICUDO, 2013, p. 417)

\section{Em direção a um entendimento de Educação Tecnológica: na transitoriedade de conclusões}

Quanto mais próximos estamos da atualidade, mais nitidamente vemos na história e na filosofia o estreitamento entre ciência e técnica. A complexidade e entrelaçamento são intensos, o que nos traz cada vez mais dificuldades em separar ciência e tecnologia, pois cada uma pode contribuir com a reelaboração da outra. Por exemplo, a microeletrônica tem contado com a ciência para desenvolver tecnologia e, num mesmo movimento produtivo, a tecnologia tem favorecido o desenvolvimento dessa área. Isso quer dizer que cada vez mais temos a produção do conhecimento e, muitas vezes, não se distingue claramente as fronteiras. Bazzo (2011) vem falando sobre isso e, para ele, "A humanidade vive, mais do que nunca, sob os auspícios e domínios da ciência e da tecnologia e isso ocorre de modo tão intenso e marcante que é comum muitos confiarem nelas como se confia numa divindade" (BAZZO 2011, p. 92). Essa confiança vem se dando de modo crescente e muitos dos significados da tecnologia têm sido absorvidos pelo uso que se faz de instrumentos que trazem sentido orientador diverso para a produção humana.

Essa visão também é exposta por Santos (2001) ao entender três tipos de mundo, quando estuda o fenômeno da globalização, a saber: o mundo como fábula, como perversidade e como possibilidade. O primeiro se refere ao mundo como nos fazem acreditar, um mundo que tudo parece se aproximar, as distâncias se tornam curtas e há um bombardeio de informações, há a busca de uniformidade, de união, mas ao mesmo tempo se torna menos unido (SANTOS, 2001). O segundo, o mundo como é, ou seja, considerada por Santos (2001) como perverso, por se destacar o comportamento competitivo que caracteriza as ações hegemônicas. O terceiro, o mundo como pode ser, ou seja, uma outra globalização, evidencia a abertura que o mundo pode vir a se constituir, focalizando uma globalização mais humanizada, tendo a unicidade da técnica como base da globalização perversa, mas

[...] essas mesmas bases técnicas poderão servir a outros objetivos, se forem postas ao serviço de outros fundamentos sociais e políticos. Parece que as condições históricas do fim do século XX apontavam para esta última possibilidade. Tais novas condições tanto se dão no plano empírico quanto no plano teórico (SANTOS, 2001, p. 20). 
Dada a complexidade do tema, Bazzo (2011), Mello (1989) e Rodrigues (1999) clamam pela necessidade de uma filosofia da tecnologia, pois

A tese da dependência social da ciência e tecnologia vem ganhando adeptos e adquirindo uma presença cada vez mais forte, empurrando as instituições que trabalham com essas áreas a buscar subsídios nos campos sociológicos e epistemológicos que possam ajudar a desvendar e a resolver algumas dependências que influenciam sobremaneira o aprendizado [...] (BAZZO, 2011, p. 127).

De acordo com os rumos que o trabalho seguiu, entendemos que a Educação Tecnológica se preocupa em cuidar do mundo da educação, do trabalho e da produção de conhecimentos, uma vez que devido ao modo como nos ocupamos com as coisas, temos a possibilidade de transformar e nos transformar, ao estarmos junto das pessoas e das coisas que povoam o mundo.

E a tecnologia? Pautados nos estudos heideggerianos temos que tecnologia não é

[...] uma coisa, que seria o maquinismo, nem mesmo um outro e simples saber: tratase de construção do mundo em dadas condições. A tecnologia é formadora de uma época, expressa um modo de ser que abre um mundo, na medida em que é a correspondência entre um processo de posicionamento da realidade e uma forma de pensamento (RÜDGER, 2006, p.19).

Os entendimentos possíveis neste estudo nos abrem à importância da formação tecnológica e Matemática de cidadãos para enfrentar as complexidades do mundo contemporâneo, numa presença articuladora, como defendida por Ponte (2002). Buscou-se clarear significados de educação tecnológica que favoreçam transcender a compreensão de tecnologia como aplicação de recursos tecnológicos na Educação Matemática, que muitas vezes se destacam pelos objetivos de um ensino para a fixação de conteúdos escolares.

A exploração, no ensino de Matemática, de atividades que envolvam novas possibilidades de experimentação, visualização, multimodalidade e simulação, por exemplo, podem colaborar para a compreensão das tecnologias de modo não alienante e romantizada, tal como apontado por Bazzo (2011), mas como algo que caminha para além do que ela mesma produz, num sentido heideggeriano.

O desafio que se impõe, cada vez mais, é compreender a educação tecnológica e nos compreendermos professores de Matemática nessa perspectiva, rompendo as fronteiras dos mundos escolar e social, pela produção do conhecimento com tecnologia, questionando o que 
temos feito; por que desse modo e não de outro?; intencionalmente voltados a compreender o que temos e o uso para que, como construtores do mundo, o habitemos.

\title{
TECHNOLOGY, EDUCATION AND TECHNOLOGICAL EDUCATION: HERITAGES AND ADDRESSES
}

\begin{abstract}
This article aims to discuss meanings attributed to technology and the production of knowledge with technology in the school context, having in the background these meanings in Mathematics Education. In consideration of the guiding question "What understandings may be possible when we look at the technology-education meeting?" We study authors who are dedicated to the subject, seeking support from a theoreticalphilosophical background to answer it. From this study we outline a course of exposition of our understandings, starting with a section that aims to demarcate the insertion of technology in Brazilian education. We continue by opening a discussion about historical nuances of technologies in Mathematics Education in Brazil and finalizing our text by having dialogues with the ideas of Martin Heidegger towards an understanding of technological education. According to this author, "to have" and "to use" technologies request to be seen in the movement of producing knowledge, transforming learning and teaching, to inhabit the world classificated as technological.
\end{abstract}

Keywords: Education. Technology. Mathematical Education. Knowledge Production. Technological Education.

\section{Referências}

ALMEIDA, M. E. B. Educação e tecnologias no Brasil e em Portugal em três momentos de sua história. Educação, Formação \& Tecnologias, Portugal, v. 1, n. 1, 2008a, p. 23-36. Disponível em <http://eft.educom.pt/index.php/eft/article/view/19>. Acesso em: 9 nov. 2016.

ALMEIDA, M. E. B. Tecnologias na educação: dos caminhos trilhados aos atuais desafios.

Bolema, Rio Claro, v. 21, n. 29, 2008b, p. 99-129. Disponível em <http://www.redalyc.org/pdf/2912/291221870006.pdf>. Acesso em: 9 nov. 2016.

BAZZO, W. A. Ciência, tecnologia e sociedade: e o contexto da educação tecnológica. 3. ed. Florianópolis: UFSC, 2011.

BAZZO, W. A. Ponto de Ruptura Civilizatória: a Pertinência de uma Educação "Desobediente". Revista CTS, n. 33, v. 11, setembro, 2016, p. 73-91.

BICUDO, M. A. V. Ensino de Matemática e Educação Matemática: algumas considerações sobre seus significados. Bolema, Rio Claro, v.12, n. 13, p. 1-11, 1999.

BICUDO, M. A. V. Pesquisa qualitativa: significados e a razão que a sustenta. Revista Pesquisa Qualitativa, São Paulo, ano 1, n.1, p.7-26, 2005. 
BICUDO, M. A. (ORG). Pesquisa qualitativa segundo a visão fenomenológica. São Paulo: Cortez, 2011.

BORBA, M. C.; PENTEADO, M. G. Informática e Educação Matemática. Belo Horizonte, MG: Autêntica, 2012.

BORBA, M. C.; SILVA, R. S. R.; GADANIDIS, G. Fases das tecnologias digitais em

Educação Matemática. Belo Horizonte: Autêntica, 2016. (Coleção Tendências em Educação Matemática).

CANDAU, V. M. F. Tecnologia Educacional: concepções e desafios. Cadernos de pesquisa da Fundação Carlos Chagas, São Paulo, n. 28, mar. 1979, p. 61-66.

FERNANDES, M. A. Do cuidado da fenomenologia à fenomenologia do cuidado. In: Adão José Peixoto; Adriano Furtado Holanda. (orgs.). Fenomenologia do cuidado e do cuidar: perspectivas multidisciplinares. Curitiba: Juruá, 2011, p. 17-31.

FIGUEIREDO, O, A. A questão do sentido em computação. In: BICUDO, M. A. V. (Org.). Ciberespaço: Possibilidades que abre ao mundo da educação. São Paulo: Editora Livraria da Física, 2014.p. 109-149.

FIORENTINI, D. Alguns modos de ver e conceber o ensino de matemática no Brasil.

Zetetiké, Campinas, a. 3, n. 4, p.1-37, 1995.

GRINSPUN, M. P. S. Z. Educação tecnológica: desafios e perspectivas. São Paulo: Cortez, 1999.

HEIDEGGER, M. Ensaios e conferências. Tradução de Emmanuel Carneiro Leão, Gilvan Foge, Marcia Sá Cavalcante Schuback. 8.ed. Petrópolis: Vozes; Bragança Paulista:

Universitária São Francisco, 2012. (Coleção Pensamento Humano).

ISOTANI, S. BRANDÃO, L. O. O Papel do Professor e do Aluno Frente ao Uso de um Softwares de Geometria Interativa: iGeom. Bolema, Rio Claro (SP), v. 27, n. 45, p. 165-192, abr. 2013.

KALINKE, M. A.; MOCROSKY, L. F. A Lousa Digital e outras tecnologias na Educação Matemática. Curitiba: Editora CRV, 2016.

KENSKI, V. M. Educação e tecnologias: o novo ritmo da informação. 6. ed. Campinas: Papirus, 2007.

LÉVY, P. As tecnologias da inteligência: o futuro do pensamento na era da informática. Rio de Janeiro: Editora 34, 1993.

MALTEMPI, M. V. Construcionismo: pano de fundo para pesquisas em informática aplicada à educação matemática. In: BICUDO, M. A. V.; BORBA, M. C. (orgs.). Educação

Matemática: pesquisa em movimento. São Paulo: Cortez, 2004. p. 264-282.

MELLO, L. G. Tecnologia educacional: busca de significados. In: BAQUERO, R. V. (org.). Educação e técnica: possibilidade e impasses. Porto Alegre: Kuarup, 1989. p. 53-72. 
MOCROSKY, L. F. A Presença da Ciência, da Técnica, da Tecnologia e da Produção no Curso Superior de Tecnologia em Fabricação Mecânica. 2010. 364 f. Tese (Doutorado) Instituto de Geociências e Ciências Exatas, Universidade Estadual Paulista, Rio Claro, 2010.

MOCROSKY, L. F. et al. Sobre precisão e necessidade: um pensar acerca da tecnologia e Educação Matemática. KALINKE, M. A.; MOCROSKY, L. F. A Lousa Digital e outras tecnologias na Educação Matemática. Curitiba: Editora CRV, 2016.

MOCROSKY, L. F.; BICUDO, M. A. V. Um estudo filosófico-histórico da ciência e da tecnologia sustentando a compreensão de educação científico-tecnológica. Acta Scientiae. v.15, n.3, p. 406-419, set./dez. 2013.

MOCROSKY, L. F.; MONDINI, F.; BAUMANN, A. P. A EaD na perspectiva da legislação brasileira. In: BICUDO, M. A. V. (Org.). Ciberespaço: Possibilidades que abre ao mundo da educação. São Paulo: Editora Livraria da Física, 2014. p. 153-184.

MORAES, M. C. Informática educativa no Brasil: uma história vivida, algumas lições aprendidas. Revista Brasileira de Informática na Educação, Porto Alegre, v. 1, n. 1, p. 1944, 1997.

NASCIMENTO, O. V. Cem anos de ensino profissional no Brasil. 20. ed. Curitiba: Ibpex, 2007.

OLIVEIRA, L. M., et al. A educação tecnológica no contexto das séries iniciais do ensino fundamental: a voz docente. In: Encontro Nacional de Pesquisa em Educação em Ciências, 6, Anais... Florianópolis: ABRAPEC, 2007.

PONTE, J. P da. As TIC no início da escolaridade: perspectivas para a formação inicial de professores. In: . A formação para a integração das TIC na educação pré-escolar e no 1. ${ }^{\circ}$ ciclo do ensino básico. Porto (Portugal): Porto Editora, 2002.

RICHIT, A. Apropriação do Conhecimento Pedagógico-Tecnológico em Matemática e a Formação Continuada de Professores. 2010. 279 f. Tese (Doutorado) - UNESP, Rio Claro, 2010. Disponível em:

<http://www.rc.unesp.br/gpimem/downloads/teses/tese\%20adriana\%20_richit.pdf>. Acesso em 26 jun. 2016.

RICHIT, A.; MALTEMPI, M. V. A formação de professores nas políticas públicas de inclusão digital: o programa UCA-Erechim (RS). Conjectura: Filosofia e Educação, Caxias do Sul, v. 18, n. 1, p. 17-41, jan./abr. 2013.

ORLOVSKI, N.; KALINKE, M. A.; MOCROSKY, L. F. O uso das novas tecnologias: um olhar para a formação do professor que ensina matemática nos anos iniciais. RPEM, Campo Mourão, v.3, n.4, jan.- jun. 2014.

RODRIGUES, A. M. M. Por uma filosofia da tecnologia. In: GRINSPUN, M. P. S. Z. (org.). Educação tecnológica: desafios e perspectivas. São Paulo: Cortez, 1999. p. 75-129.

RÜDGER, F. Martin Heidegger e a questão da técnica: prospectos acerca do futuro do homem. Porto Alegre: Sulina, 2006. 
SANTOS, M. Por uma outra globalização: do pensamento único à consciência universal. 6 . ed. Rio de Janeiro: Record, 2001.

VALENTE, J. A. Informática na educação no Brasil: análise e contextualização histórica. In: O computador na sociedade do conhecimento. Campinas: UNICAMP/NIED, 1999. p. 1-13.

VALENTE, W. R. (org.) Euclides Roxo e a modernização do ensino de matemática. Brasília: Universidade de Brasília, 2004.

VARGAS, M. Prefácio. In: GRINSPUN, M. P. S. Z. (org.). Educação tecnológica: desafios e perspectivas. São Paulo: Cortez, 1999. p. 7-14. 